\title{
Risk Assessment of Adhesives in Contact with Food
}

Henkel has published a white paper on the topic of "Food Safe Packaging". The author is Dr. Joerg Feesche, who explains how Henkel fulfils both customer demands and legal requirements.

O ne important premise of food contact legislation is preventing food contact materials from endangering human health. It is the responsibility of the manufacturer of the food contact material to check whether their material releases certain chemicals and to assess whether these are likely to impact human health. However, there is no special regulation explicitly covering food contact adhesives. In his white paper, Dr. Joerg Feesche provides a summary as well as information and insights into relevant regulations and risk assessment. Anyone interested can visit the website at www.henkel.com/ foodsafety to register for the premium area, where the white papers can be found along with a glossary and videos on food safe packaging adhesives.

\section{Adhesive Bonding Technology at the Hannover Messe 2014}

$T$ he importance of industrial adhesive grow. Numerous innovations - particularly in the field of lightweight construction - would hardly be possible today without this modern joining technology. For that reason, Hannover Messe (Hannover Fair), which takes place from 11 to 14 April, will once again focus on adhesive technology. At Industrial Supply, probably the most important suppliers' trade fair in the world, companies involved in adhesive bonding present their products and services in the themed presentation Themenpark Kleben.

For further information, please visit: www. hannovermesse.de

Dr. Joerg Feesche, adhesives expert at Henkel, has written a white paper entitled "How to Determine the Safety of a Food Contact Adhesive".
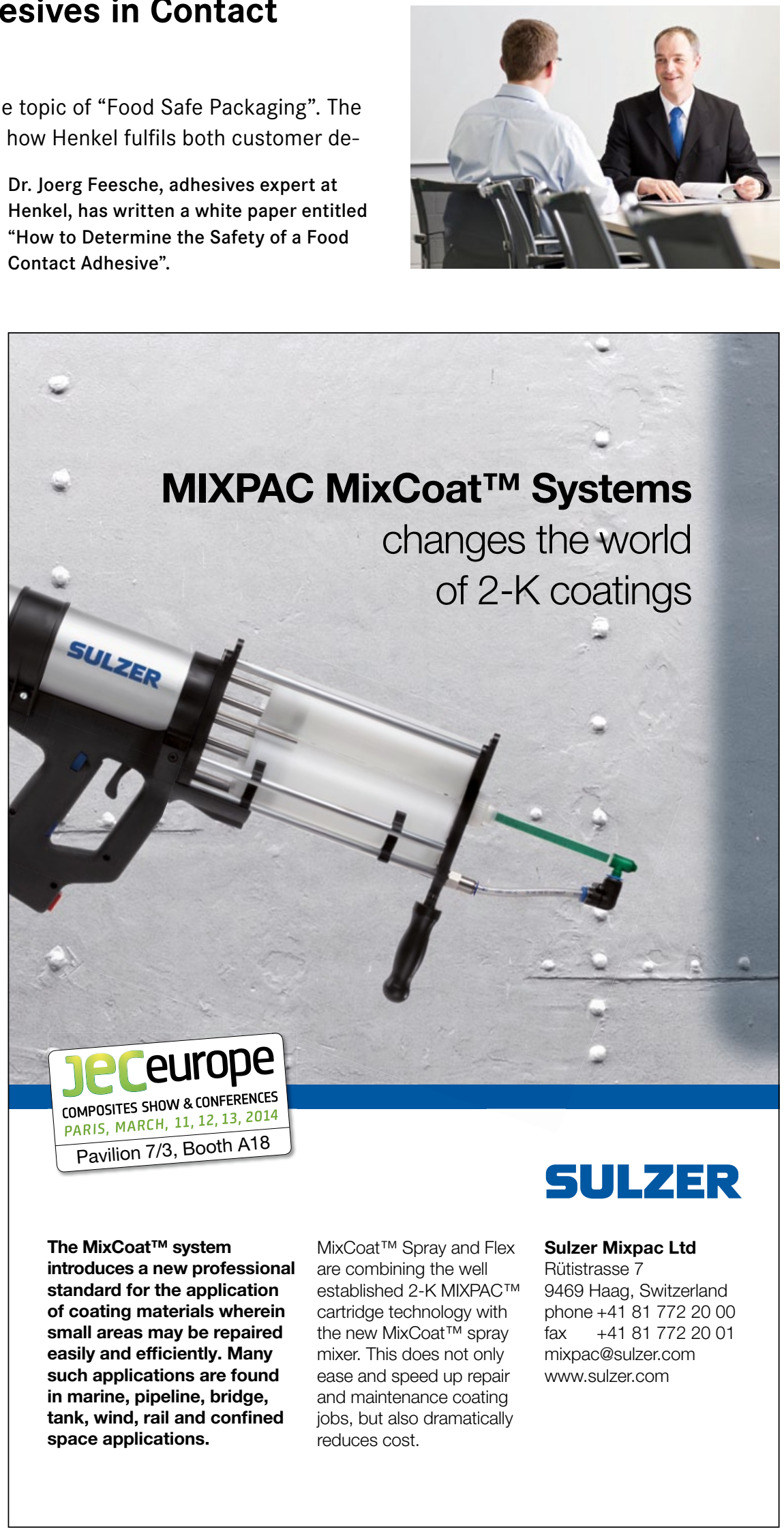